framum

Sociológico

\section{Forum Sociológico}

Série II

$34 \mid 2019$

Habitação nas áreas urbanas de Lisboa e Porto: Da comunidade aos decisores políticos

\title{
Política de habitação social em Portugal: de 1974 à actualidade
}

Social housing policy in Portugal: from 1974 to the present

\section{Gonçalo Antunes}

\section{(2) OpenEdition \\ Journals}

Edição electrónica

URL: https://journals.openedition.org/sociologico/4662

DOI: $10.4000 /$ sociologico.4662

ISSN: 2182-7427

Editora

CICS.NOVA - Centro Interdisciplinar de Ciências Sociais da Universidade Nova de Lisboa

Edição impressa

Paginação: 7-17

ISSN: 0872-8380

Refêrencia eletrónica

Gonçalo Antunes, «Política de habitação social em Portugal: de 1974 à actualidade», Forum

Sociológico [Online], 34 | 2019, posto online no dia 19 agosto 2019, consultado o 29 março 2022. URL: http://journals.openedition.org/sociologico/4662 ; DOI: https://doi.org/10.4000/sociologico.4662 


\title{
POLÍTICA DE HABITAÇÃO SOCIAL EM PORTUGAL: DE 1974 À ACTUALIDADE SOCIAL HOUSING POLICY IN PORTUGAL: FROM 1974 TO THE PRESENT
}

\author{
Gonçalo Antunes \\ Centro Interdisciplinar de Ciências Sociais (CICS.NOVA), Faculdade de Ciências Sociais e Humanas (NOVA FCSH)
}

\begin{abstract}
Resumo
Quando, em 1974, se deu a Revolução de 25 de Abril, o "problema da habitação" estava entre os maiores atrasos do nosso país. O presente artigo tem como objectivo analisar as políticas de habitação social promulgadas em Portugal desde Abril de 1974. O estudo incide, em particular, no quadro legislativo das políticas de habitação social, de promoção directa e de promoção indirecta, pretendendo-se compreender a evolução temporal do "direito à habitação" na democracia portuguesa. A metodologia adoptada assenta na interpretação crítica dos diplomas legais publicados e dos respectivos programas habitacionais, assim como na pesquisa de estudos que analisam do ponto de vista teórico e prático as políticas habitacionais abordadas ao longo do trabalho. A análise cronológica, que tem como base a evolução legislativa, demonstra que no nosso país as políticas de habitação social foram essencialmente casuísticas, circunstanciais e pontuais, não se tendo criado a médio ou a longo prazo uma estratégia de promoção de habitação social apoiada pelo Estado.
\end{abstract}

Palavras-chave: políticas de habitação, direito à habitação, habitação social

\begin{abstract}
When the revolution of April 25 occurred in 1974, the "housing problem" was one of the main social issues at the time in Portugal. The purpose of this article is to analyze the social housing policies promulgated in Portugal since April 1974. The study focuses on social housing legislation, aiming to understand the evolution of the "right to housing" in the Portuguese democracy. The methodology adopted is based on the critical interpretation of the legislation and the housing programs created, as well as on the analysis of studies about the theoretical and practical results of the housing policies addressed throughout the work. The chronological analysis, based on the legislative evolution, shows that in Portugal social housing policies were essentially casuistic and circumstantial, without a medium-term or long-term strategy for the promotion of social housing supported by the State.
\end{abstract}

Keywords: housing policies, right to housing, social housing

\section{Políticas de habitação: propostas de análise e interpretação}

O percurso das políticas de habitação social em Portugal tem sido estudado ao longo das últimas décadas, com abordagens diferenciadas que procuram compreender a evolução das políticas de habitação nos domínios da Sociologia, Arquitectura, Urbanismo, Geografia, Ciência Política, entre outros. Este trabalho segue, assim, uma linha interpretativa que encontra paralelo em outros trabalhos, embora com abordagens científicas, metodológicas e períodos diferenciados.

É disto exemplo o trabalho de Baptista (1999), que se focou nas políticas de habitação social promulgadas durante o Estado Novo e, em particular, sobre a política de casas económicas. Outros autores, como Gros (1994), também analisaram a história do alojamento social no período da ditadura, ou Silva (1994a, 1994b, 1994c, 1997), que relacionou as políticas de habitação, urbanas e fundiárias para o mesmo período. 
No mesmo sentido, também Serra (2002) analisou a questão das políticas de habitação, interligando as estratégias habitacionais aplicadas na segunda metade do século XX. Também o IHRU, num trabalho coordenado por Portas (2013), analisou algumas das principais políticas de habitação social - assim como o problema da habitação - na transição entre a ditadura e a democracia. Por sua vez, Ferreira $(1987,1993)$ focou-se no estudo sequencial das políticas de habitação promulgadas nas primeiras duas décadas após a revolução, assim como naquilo que ainda faltava fazer no início da década de 1990. Numa análise mais relacionada com a arquitectura, também Coelho $(2006,2009)$ examinou o objecto construído nas políticas de habitação social na transição entre os séculos XX e XXI. Mais recentemente, Guerra (2011) reflectiu sobre os novos caminhos para as políticas de habitação e Acciaiuoli (2015) observou a história da habitação em Lisboa entre o início do século XIX e o final do século XX, numa abordagem relacionada com o mercado de habitação privado e de arrendamento.

Em 2018, surgiram dois trabalhos que analisaram as políticas de habitação social promulgadas em Portugal. Em Novembro, Antunes (2018) publicou um trabalho que analisa de forma sistematizada as políticas de habitação promulgadas em território nacional nos últimos duzentos anos, no seu tríplice de habitação social, arrendamento e reabilitação. No mês seguinte, num projecto institucional promovido pelo Instituto da Habitação e da Reabilitação Urbana (IHRU) e coordenado por Agarez (2018), foi publicado um estudo que engloba análises às políticas habitacionais promulgadas nos últimos cem anos e respectivos resultados práticos, recorrendo, como no caso anterior, a informação estatística, acervos, arquivos, entre outros elementos que permitem a interpretação das políticas de habitação e respectivos resultados.

Este pequeno sintagma de contributos que analisam no todo ou em parte a sequência de políticas de habitação social em Portugal não esgota, como é óbvio, as várias centenas de estudos científicos que têm analisado os objectivos e os resultados de políticas de habitação particulares, de determinados bairros construídos e das vivências sociais e urbanas daí resultantes.

No que respeita à experiência internacional, são conhecidos os trabalhos que têm promovido o debate sobre a experiência e a evolução do quadro legal das políticas de habitação, destacando-se, por exemplo, vários estudos publicados sobre esta matéria no Reino Unido (Malpass \& Murie, 1999; Hughes \& Lowe, 2000; Lowe, 2011; Lund, 2016), ou de trabalhos comparativos entre diferentes países europeus (Dias, 1994; Balchin, 1996; Allen, Barlow, Leal, Maloutas \& Padovani, 2004; McCrone \& Stephens, 2017; Bargelli \& Heitkamp, 2018).

\section{Âmbito e metodologia}

O presente artigo tem como objectivo analisar a evolução do quadro legal das políticas de habitação social desde o 25 de Abril de 1974, numa análise de natureza voluntariamente teórica, qualitativa e ensaística. Para tal, o trabalho assenta na leitura crítica dos vários diplomas legislativos promulgados nos últimos 45 anos de democracia, mas, também, na análise dos seus resultados num domínio de análise eminentemente cronológico e sócio-urbano. Além da fundamental interpretação dos diplomas ${ }^{1}$, realizou-se, paralelamente, a necessária pesquisa bibliográfica de estudos que analisam do ponto de vista teórico e prático as políticas habitacionais abordadas ao longo do trabalho, tendo-se utilizado, ainda, dados estatísticos disponibilizados pelo Instituto Nacional de Estatística (INE) e pelo Instituto da Habitação e Reabilitação Urbana (IHRU).

Sobre o estudo das políticas de habitação, chama-se a atenção sobre as armadilhas conceptuais e metodológicas que a análise encerra. Como afirma Baptista (2001), colocam-se vários desafios à análise das políticas de habitação, pois, em grande medida, o seu estudo está dependente dos dados produzidos por organismos institucionais, que podem ser levados a realizar interpretações propagandísticas para legitimar as opções tomadas. Esta situação é especialmente evidente, por exemplo, nos preâmbulos da legislação produzida, que faz uso frequente de fundamentação e justificação político-ideológica para a criação de novos programas ou a revogação dos já existentes. A análise crítica, a multidisciplinariedade de conhecimentos e o cruzamento e a validação múltipla das informações devem, assim, alicerçar qualquer trabalho que pretenda analisar o quadro legal das políticas de habitação.

Do ponto de vista conceptual, entende-se neste trabalho o conceito de habitação social num sentido alargado de interesse social, incluindo todos os imóveis com vocação habitacional que para a sua construção beneficiam (ou beneficiaram) de apoios directos ou indirectos da administração pública, independentemente da variedade de modelos de produção, de financiamento, de gestão, de público-alvo e de regimes de ocupação.

O artigo está estruturado da seguinte forma: a) fundamentação do quatro teórico do trabalho e de estudos que analisam a evolução das políticas de habitação a nível nacional e internacional; b) análise do período revolucionário; c) apreciação das disposições constitucionais; d) interpretação do desenvolvimento das políticas de habitação social, debatendo-se a promoção indirecta e a promoção directa; e) reflexões finais em torno do percurso das políticas de habitação social em Portugal. 


\section{As políticas de habitação desde Abril} de 1974

\section{A revolução e o problema da habitação}

No período imediato à revolução o problema da habitação incluiu-se nas principais reivindicações da população portuguesa, sobretudo nas duas maiores cidades do país, Porto e Lisboa. No turbilhão de acontecimentos que se sucederam nos meses seguintes ao 25 de Abril, ocorreram dezenas de acções populares, mobilizações sociais e manifestações que reivindicavam melhores condições de vida e que pretendiam trazer o problema da habitação para a ordem do dia (Cerezales, 2003; Bandeirinha, 2007; Pinto, 2008; 2013; Acciaiuoli, 2015).

O exemplo mais expressivo destas acções ficou plasmado na ocupação de casas devolutas, o que se traduziu num dos fenómenos urbanos mais singulares do pós-25 de Abril. Para além destas acções espontâneas de índole anarco-populista (Santos, 2017), o período revolucionário ficou ainda marcado pela organização comunitária. Afirma Pinto (2008, 2013) que entre Abril de 1974 e Julho de 1976 foram criadas 166 organizações comunitárias só na cidade de Lisboa, entre comités de ocupantes, comissões de moradores, de inquilinos, entre outros.

Foi neste ambiente de participação activa das comunidades locais que se criaram as condições ideais para a implementação de políticas de habitação que instigassem a participação directa da população. Tal viria a materializar-se no Verão de 1974, com a criação do Serviço de Apoio Ambulatório Local (SAAL). ${ }^{2}$ O SAAL pretendia contribuir para a diminuição do número de bairros de habitações precárias, tendo rompido com diversos paradigmas das intervenções do Estado Novo. A metodologia SAAL rejeitava os processos tipicamente top-down e privilegiava uma abordagem bottom-up, que pretendia fomentar a governação de proximidade e a participação da população. Para tal, eram constituídas brigadas ambulatórias que funcionavam na órbita do Fundo de Fomento da Habitação (FFH), sendo compostas por equipas multidisciplinares (Bandeirinha, 2007). As brigadas entravam em diálogo directo com as comissões de moradores, debatendo-se em sessões de esclarecimento as tipologias habitacionais a serem construídas no novo bairro, de forma a que estivessem de acordo com as expectativas da população que, em muitas situações, era convidada a participar na construção das casas e do bairro, num modelo de autoconstrução.

A metodologia aplicada no SAAL pode ser catalogada com a democracia directa e participativa, que perdeu força à medida que a democracia representativa se consolidou no nosso país, ao que se juntava um clima político-partidário que olhava com desconfiança para o SAAL (Bandeirinha, 2007;
Cerezales, 2003; Pinto, 2013; Ferreira, 1987). Foi neste contexto que, em 1976, o SAAL sofreu diversas alterações com o objectivo prático de revogar o Serviço. ${ }^{3}$ Em resposta, o Conselho Nacional do SAAL (CNS) apressou-se a elaborar um "livro branco", que indicava que até Outubro de 1976 foram registados 246 pedidos de intervenção em todo o país, tendo sido iniciadas 170 operações com um potencial de abranger 41665 famílias. Contudo, os números das concretizações eram mais modestos, indicando-se até à mesma data a construção de 2259 fogos e estando prevista a edificação a curto prazo de mais 6000 habitações (CNS, 1976).

\section{A Constituição da República Portuguesa}

Numa clara assunção progressista, a Constituição da República Portuguesa (CRP) consagra o direito à habitação, no Art. $65 .^{\circ}$, referindo-se no primeiro ponto deste artigo: "1. Todos têm direito, para si e para a sua família, a uma habitação de dimensão adequada, em condições de higiene e conforto e que preserve a intimidade pessoal e a privacidade familiar."

Não obstante pequenas alterações nas décadas seguintes, o Art. $65 .^{\circ}$ manteve o seu sentido programático para incentivar a administração pública a assegurar o direito à habitação, mas não de forma necessariamente vinculativa, como ocorre noutros direitos constitucionais. No âmbito da revisão constitucional de 2001 , o Art. $65 .^{\circ}$ foi alterado para "Habitação e Urbanismo" e o seu conteúdo reflecte actualmente uma redacção que incorpora questões como a habitação, o urbanismo e o ordenamento do território. Actualmente, a questão do acesso à habitação está também incluída no Art. $72 .^{\circ}$ ("Terceira Idade") 4 e no Art. 70. ("Juventude") 5 .

O Art. $65 .^{\circ}$ foi, logo em 1976, vanguardista ao consagrar o direito à habitação, o que está longe de ocorrer em todas as constituições europeias (Farha, 2017), mesmo nos países que mais investiram no Estado Social na segunda metade do século XX. Paralelamente, o progressismo do Art. $65 .^{\circ}$ pode também ser aferido ao assumir preocupações com a rede de transportes e de equipamentos sociais, assim como a necessidade de apoiar especificamente as "iniciativas das comunidades locais" (i. e., associações e comissões de moradores), a "autoconstrução", as "cooperativas de habitação" e, também, "políticas tendentes a estabelecer um sistema de renda compatível com o rendimento familiar".

A promoção indirecta: cooperativas e iniciativa privada

As cooperativas de habitação

Em Portugal a acção das cooperativas de habitação era possível desde Oitocentos, ao abrigo da 
Lei Basilar do Cooperativismo de 1867. Contudo, a actividade destas entidades foi sempre incipiente, ainda no século XIX, devido à inexperiência com o modelo cooperativo, e, mais tarde, durante a ditadura, as cooperativas de habitação estavam dependentes da capacidade de autofinanciamento, funcionando essencialmente como Caixas de Crédito Imobiliário, ao que acrescia a desconfiança política do movimento cooperativo (Ferreira, 1987; Matos, 1994; CET, 1994; Pedrosa, 2018; Antunes, 2018).

Foi após a revolução que foram criadas as condições para fomentar a acção das cooperativas de habitação (FFH, 1979). Em Dezembro de 1974, foi publicado o Regime Jurídico da Cooperação Habitacional6, que regulava a constituição das cooperativas de habitação, e um outro diploma que especificava os apoios para as denominadas Cooperativas de Habitação Económica $(\mathrm{CHE})^{7}$, ou seja, as cooperativas que tivessem por objectivo construir ou adquirir habitações de interesse social.

Não obstante os dois diplomas publicados em Dezembro de 1974 - cujo objectivo foi fomentar a actividade das cooperativas de habitação e de modernização jurídica conforme a realidade internacional -, a acção destas entidades manteve-se incipiente, em grande medida devido à indefinição dos apoios financeiros (Ferreira, 1987). Embora existisse legislação que regulasse o funcionamento das $\mathrm{CHE}$, o esquema de apoio financeiro apenas foi definido em 1977, num sistema análogo ao regime de crédito geral, o que desagradou às cooperativas e impediu que a actividade se desenvolvesse (FFH, 1979). ${ }^{8}$ Esta situação apenas foi ultrapassada no ano seguinte, depois de ter sido promulgado um novo diploma que instituiu um esquema de financiamento mais vantajoso para as $\mathrm{CHE} .{ }^{9}$ No preâmbulo deste novo diploma, o legislador fazia questão de sublinhar a importância das cooperativas de habitação e explicava em que medida estas podiam substituir a função do Estado, sobretudo no que dizia respeito ao acesso a casa própria por parte de famílias da classe média. Embora o esquema de apoio financeiro tenha sido definido de forma satisfatória em 1978, este período coincidiu com a primeira intervenção do Fundo Monetário Internacional (FMI), o que afectou as verbas públicas que podiam ser alocadas. Desta forma, a actividade das cooperativas de habitação manteve-se com sérias dificuldades.

Na década de 1980 surgiram mais alterações legislativas importantes, como o Código Cooperativo $^{10}$, que pretendia reformar e regular a acção de todo o movimento cooperativo. O Código Cooperativo integrava as cooperativas de habitação no ramo das "cooperativas de construção e habitação", que estava dependente de legislação própria a publicar. No preâmbulo do Código Cooperativo era indicado que existiam, em 1974, cerca de 40 cooperativas de habitação activas (4,2\% do universo cooperati- vista), número que subiu para 258 em 1979 (7,2\% do universo cooperativista).

Em 1982 surge a legislação própria das "cooperativas de construção e habitação"11 - conforme era exigido no Código Cooperativo de 1980 -, revogando os dois diplomas publicados em 1974. Nos anos seguintes ocorreram diversas alterações legislativas, sobretudo nos modelos de financiamento, adaptações às alterações institucionais, direccionamento dos financiamentos para a aquisição de casa própria e condicionamento dos financiamentos ao cumprimento das limitações estabelecidas para a "habitação social"12 e, posteriormente, "habitação a custos controlados"13.

No que respeita à experiência das cooperativas, salienta-se que entre 1974 e 1979 existiu uma explosão significativa na formação de cooperativas de habitação (Coelho, 2013; Pedrosa, 2018). Apesar do forte crescimento, o número de fogos construídos manteve-se reduzido até 1980, devido à tardia consolidação dos apoios financeiros e ao pedido de ajuda externa. De acordo com dados do INE $^{14}$, entre 1974 e 1980 foram construídos 1512 fogos, numa média de 252 fogos anuais, o que representava, para o mesmo período analisado, cerca de $5 \%$ dos fogos construídos em território nacional. Nos anos seguintes, as alterações legislativas que estabilizaram os apoios permitiram que, entre 1985 e 1995, se consolidasse o momento mais produtivo da história das cooperativas de habitação no nosso país. Entre 1980 e 1990 foram construídos 18856 fogos, numa média anual de 1886 habitações. Nos primeiros anos da década de 1990, o número anual de fogos construídos era superior a 3000 fogos por ano, tendo ultrapassado, em 1993, os 4000 fogos anuais, o que representava cerca de $6 \%$ dos fogos construídos.

Estudos concretizados no início da década de 1990 pela Federação Nacional de Cooperativas de Habitação Económica (FENACHE) apontam para a existência de 395 cooperativas de habitação (das quais 200 deviam estar activas), constituídas por 60000 cooperadores (FENACHE, 1991, 1992). Os levantamentos e estudos concretizados pelo Centro de Estudos do Cooperativismo Habitacional, da FENACHE, indicam que, entre 1974 e 1990, foram construídos cerca de 30000 fogos por cooperativas de habitação, número que ultrapassa em cerca de 10000 fogos os dados do INE para o mesmo período (FENACHE, 1991).

Depois da explosão da construção de fogos por cooperativas de habitação entre 1985 e 1995, a actividade voltou a diminuir, até regressar a valores residuais no século XXI. Do ponto de vista espacial, as cooperativas de habitação construíram habitações em todos os distritos, com especial incidência nas Áreas Metropolitanas de Lisboa e do Porto (Pedrosa, 2018). Importa salientar que mesmo no período de 
maior actividade as cooperativas de habitação se debateram com vários obstáculos, destacando-se o problema fundiário, situação que era resolvida, em parte, pela disponibilização de solos municipais em direito de superfície. Neste propósito, a articulação com os municípios foi essencial para alavancar a actividade das cooperativas de habitação, que, de outra forma, teriam dificuldades para adquirir os terrenos necessários para a construção de empreendimentos habitacionais de interesse social (Matos, 1994).

Ainda na década de 1980, estudos que analisaram a actividade das cooperativas de habitação denunciavam que estas entidades estavam a focalizar a construção para a classe média (FFH, 1980; LNEC, 1989). Tal como aponta Matos (1994), no decorrer da década de 1980 a classe social que recorria às cooperativas de habitação foi alterada, desvirtuando-se o ideal cooperativista e transformando-se estas entidades em "cooperativas-empresas".

\section{A iniciativa privada apoiada pelo Estado}

Em Novembro de 1974 foi criado o programa Contratos de Desenvolvimento para Habitação $(\mathrm{CDH}) .{ }^{15}$ Esta medida era, na verdade, uma reforma da política de casas de renda limitada, que existia desde $1947^{16}$ e que tinha sido alvo de várias alterações em $1973^{17}$ (Antunes, 2018). A política $\mathrm{CDH}$ tinha como objectivo despertar a indústria da construção para a promoção de casas de interesse social (Ferreira, 1987). Para tal, foram estipulados vários benefícios, como apoio técnico do $\mathrm{FFH}$, financiamento em condições favoráveis, isenções fiscais, garantia de compra das habitações pela administração pública, acesso a terrenos em condições vantajosas, entre outros. A política $\mathrm{CDH}$ pretendia aumentar a oferta de habitações para a classe média urbana, num esquema que reduzia os custos de construção e assegurava, à partida, o lucro das empresas privadas e a diminuição de risco empresarial. Este conjunto de benefícios não foi suficientemente aliciante para as construtoras, sendo que, de acordo com dados do INE, o número de habitações construídas foi residual.

Para alterar esta conjuntura, sucederam-se inúmeras alterações legislativas ao programa $\mathrm{CDH}$. Entre 1976 e 1985, contam-se cinco grandes alterações, que alteraram substancialmente a filosofia inicial do programa, e que no sentido geral tinham como objectivo descentralizar a medida e reduzir o risco empresarial (Ferreira, 1987; Antunes, 2018). Em 1985, o programa CDH foi alvo de uma ampla reforma ${ }^{18}$ que tinha como propósito relacionar o programa com as orientações referentes às Habitações a Custos Controlados (HCC). Estas alterações tiveram como objectivo reduzir a intervenção do Estado, desburocratizar e flexibilizar o processo administrativo e privilegiar a aquisição de casa própria. Depois de uma nova alteração em 1989, o programa consolidou-se em 1993, na sua última redacção. ${ }^{19}$ Embora em moldes jurídicos ligeiramente diferentes, também as cooperativas de habitação estão incluídas na promoção de HCC.

De acordo com o $\operatorname{INE}^{20}$, o número de habitações construídas pela iniciativa privada ao abrigo desta política foi sempre diminuta, contando-se, entre 1974 e 1992, a construção de 17807 fogos em território nacional, a maioria nos distritos do Porto (14\%), Setúbal (11\%) e Lisboa (10\%). No século XXI a construção diminuiu para valores residuais.

A promoção directa: construção do parque habitacional público

Na transição entre as décadas de 1970 e 1980, os projectos mais significativos de promoção directa estavam relacionados com os Planos Integrados do $\mathrm{FFH}$, que vinham ainda da ditadura e atravessavam dificuldades no seu desenvolvimento (Ferreira, 1987). No início da década de 1980, a promoção de habitação pública ficou ainda mais indefinida quando, em 1982, o FFH foi extinto, tendo sido substituído pelo efémero Fundo de Apoio ao Investimento para Habitação, substituído dois anos depois pelo Instituto Nacional de Habitação (INH), ao qual se juntou, em 1987, o Instituto de Gestão e Alienação do Património Habitacional do Estado (IGAPHE). Além destas alterações institucionais, foi ainda neste período que o legislador definiu o conceito de "habitação social"21 e estabeleceu os parâmetros mínimos e máximos para a construção deste tipo de habitações pela iniciativa pública, privada e cooperativa. Anos mais tarde, o legislador substituiu conceito de "habitação social" por "habitações a custos controlados"22, o que se manteve, posteriormente, em $1997^{23}$.

No meio destas alterações legais e institucionais, foram promulgados programas que definiam condições especiais de acesso ao crédito para os municípios, com o objectivo de estimular a promoção directa de habitações e a conservação do parque público existente, tal como ocorreu em $1983^{24}$ e $1985^{25}$. Contudo, os reduzidos apoios financeiros e a instabilidade institucional - que apenas foi estabilizada com a criação do INH e do IGAPHE - fizeram com que os programas referidos não tivessem a aceitação e a colaboração necessária por parte do poder local (Antunes, 2018).

A primeira grande alteração a este cenário ocorreu pela promulgação do Decreto-Lei n. ${ }^{\circ} 226 / 87$, de 6 de Junho, que estabeleceu de forma concreta o regime de cooperação entre a administração central e local para a celebração de protocolos para a construção de habitação social para arrendamento. Desta forma, foram esclarecidas as responsabilidades e as competências dos poderes central e local e, simultaneamente, foi definido um modelo de apoio 
para todo o território nacional, em que os municípios interessados poderiam candidatar-se e, posteriormente, aceder a financiamento a fundo perdido, do IGAPHE, e empréstimos favoráveis, do INH.

Ao abrigo destes diplomas foram contratualizados alguns programas de realojamento, como foi o caso do município de Lisboa, que, em 1987, estabeleceu o Programa de Intervenção a Médio Prazo, que previa a construção de 9698 fogos para realojamento de famílias residentes em bairros de habitações precárias existentes na capital $(\mathrm{DCH}$, 1990).

No início da década de 1990, percebeu-se que apenas uma política alargada de promoção pública poderia resolver o problema dos bairros de habitações precárias existentes nas duas áreas metropolitanas. Note-se que, conforme a Tabela 1, existiam em 1981 cerca de 46000 alojamentos familiares não clássicos em Portugal.

Tabela $1 \triangleright$ Alojamentos familiares não clássicos em Portugal, entre 1981 e 2011. INE

\begin{tabular}{c|c|c|c}
\hline $\mathbf{1 9 8 1}$ & $\mathbf{1 9 9 1}$ & $\mathbf{2 0 0 1}$ & $\mathbf{2 0 1 1}$ \\
\hline 46391 & 27642 & 27182 & 6612 \\
\hline
\end{tabular}

Foi neste contexto que, em 1993, foi publicado o Programa Especial de Realojamento (PER), que previa a concessão de apoio financeiro aos municípios para a construção ou aquisição de habitações, destinadas ao realojamento de agregados familiares residentes em alojamentos precários nas Áreas Metropolitanas de Lisboa e do Porto. ${ }^{26}$ Os mecanismos financeiros do PER eram, na realidade, relativamente semeIhantes aos definidos pelo Decreto-Lei n. ${ }^{\circ} 226 / 87$, mas, em meados da década de 1990 , juntavam-se a estes apoios financeiros e institucionais o desígnio nacional de "erradicação" dos chamados "bairros de barracas".

Nos anos seguintes, com vista ao desenvolvimento do PER, foram celebrados contratos-programa entre municípios, o INH e o IGAPHE. O desenvolvimento do PER foi bastante díspar de concelho para concelho. Enquanto municípios como Mafra, Moita, Montijo, Sesimbra, Gondomar, Porto e Valongo cumpriram a construção da totalidade dos fogos protocolados, outros municípios não foram tão expeditos e diligentes, como foi o caso da Amadora $(45 \%)$, Barreiro (41\%), Odivelas (42\%), Palmela (44\%) e Seixal (45\%). No total, foram protocolados 48416 fogos e construídos 34759 (Figura 1). Apesar de o PER se consubstanciar como um programa abrangente para as duas áreas metropolitanas, o município de Lisboa dominou com 11129 fogos protocolados, seguindo-se os concelhos da Amadora (5419) e de Matosinhos (3982).

Embora não seja uma discussão que se pretenda densificar no presente trabalho, os bairros construí- dos no âmbito do PER foram alvo de grande debate técnico, político e académico ainda no seu início (Guerra, 1994, 1999; Freitas, 1994, 1998; Pinto 1994), assim como mais recentemente (Cachado, 2013; Serpa et al., 2018), com vários alertas para a excessiva concentração e homogeneidade social dos bairros construídos, assim como para a escassez de espaços públicos de qualidade, de equipamentos colectivos, de rede de transporte adequada, apoio social à população, entre muitos outros.

Em 2004, surgiu o PROHABITA ${ }^{27}$ que, à semeIhança do antigo Decreto-Lei n. ${ }^{\circ} 226 / 87$ (revogado pelo PROHABITA), era concretizado mediante a celebração de protocolos entre os municípios e o INH. Desta forma, ao contrário do que ocorreu com o PER, o PROHABITA regulava a concessão de financiamento para a resolução de situações de carência habitacional para todo o território nacional. Este programa foi ainda importante para modificar a forma como as operações de realojamento eram traçadas, ao privilegiar-se acções de reabilitação de edifícios em detrimento da construção nova e também ao melhorar a eficiência energética do edificado social (Antunes, 2018; Xerez, Rodrigues \& Cardoso, 2018).

Pese embora a existência dos programas de promoção directa referidos, em 2011, segundo o INE, subsistiam em território nacional 6612 alojamentos familiares não clássicos, ou seja, construções precárias, abarracadas ou amovíveis (Tabela 1). Mais recentemente, no âmbito da Nova Geração de Políticas de Habitação, foram publicados o 1.0 Direito ${ }^{28}$ e o Porta de Entrada ${ }^{29}$, que substituíram o PROHABITA e funcionam como os novos mecanismos legais para a resolução dos problemas mais graves de habitação, esperando-se, nos próximos anos, os desenvolvimentos destes programas. Note-se, também, que no âmbito da preparação destas medidas, o IHRU elaborou o Levantamento nacional das necessidades de realojamento habitacional, apresentado em Fevereiro de 2018. No contexto deste levantamento, 120 concelhos não reportaram qualquer carência habitacional e 187 identificaram 25762 famílias a residir em "situações claramente insatisfatórias". Deste total, 19050 famílias residem nas $A M L$ e $A M P$, com clara predominância da $A M L$, na qual foram identificados 13828 agregados familiares, ou seja, mais de $50 \%$ do total (IHRU, 2015).

\section{A habitação social desde 1974: que percurso?}

Depois da revolução, o SAAL foi a primeira política de habitação social. O SAAL é ainda hoje apontado como uma das medidas habitacionais mais vanguardistas promulgadas no nosso país (Antunes, 2018), afirmando Vieira (1986) que o SAAL instigou o único instante de interesse internacional pela 
Figura $1 \triangleright$ Número de fogos construídos, por concelho, no âmbito do Programa Especial de Realojamento

\section{Programa Especial de Realojamento}

Número de fogos construídos

\section{Espinho}

Gondomar

Maia

Matosinhos

Porto

Póvoa de Varzim

Valongo

Vila do Conde

Vila Nova de Gaia

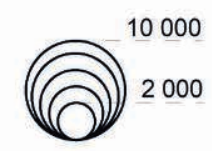

Alcochete

Almada

Amadora

Azambuja

Barreiro

Cascais

Lisboa

Loures

Mafra

Moita

Montijo

Odivelas

Oeiras

Palmela

Seixal

Sesimbra

Setúbal

Sintra

Vila Franca de Xira

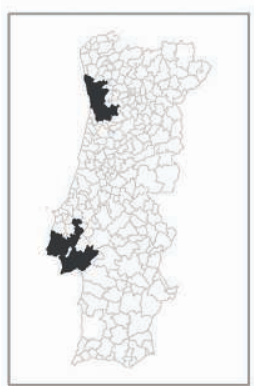

$10 \mathrm{~km}$

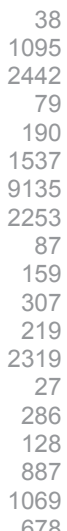

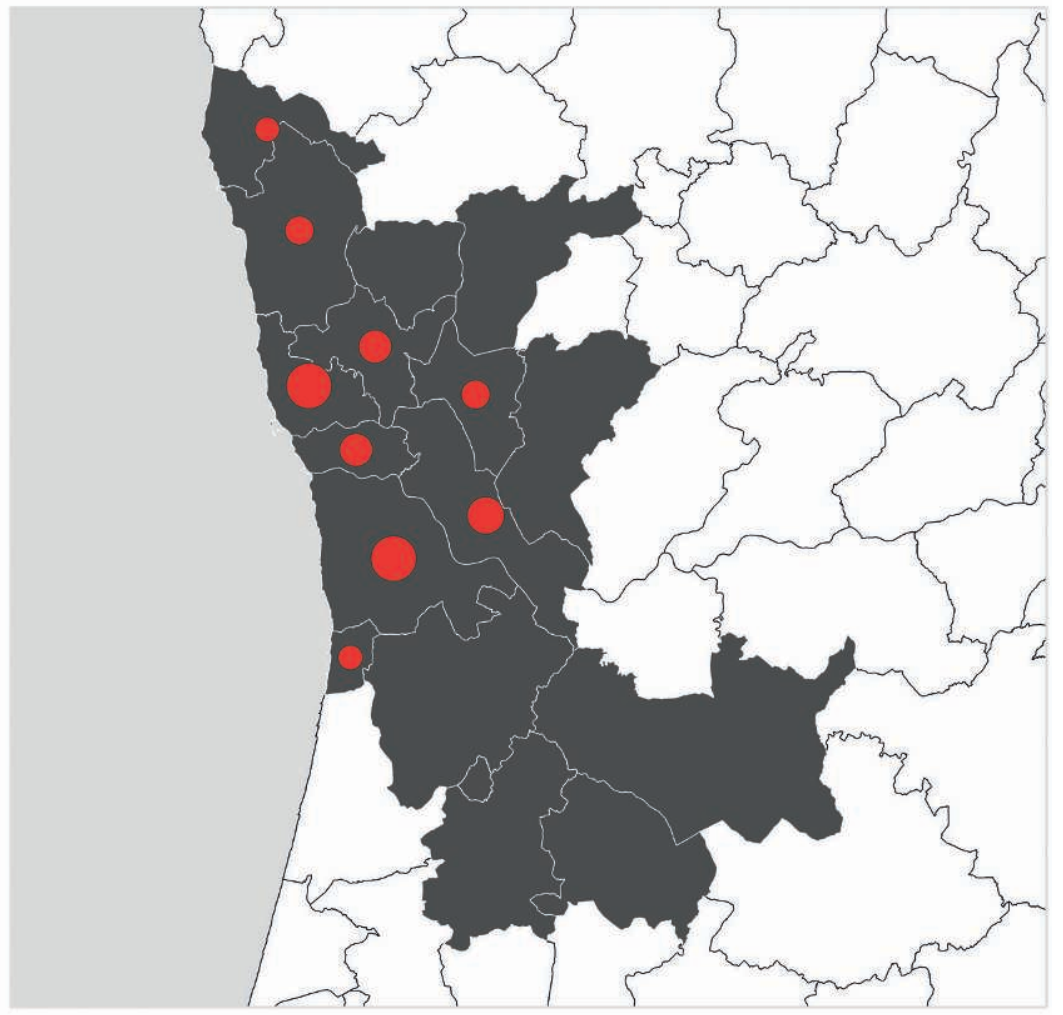

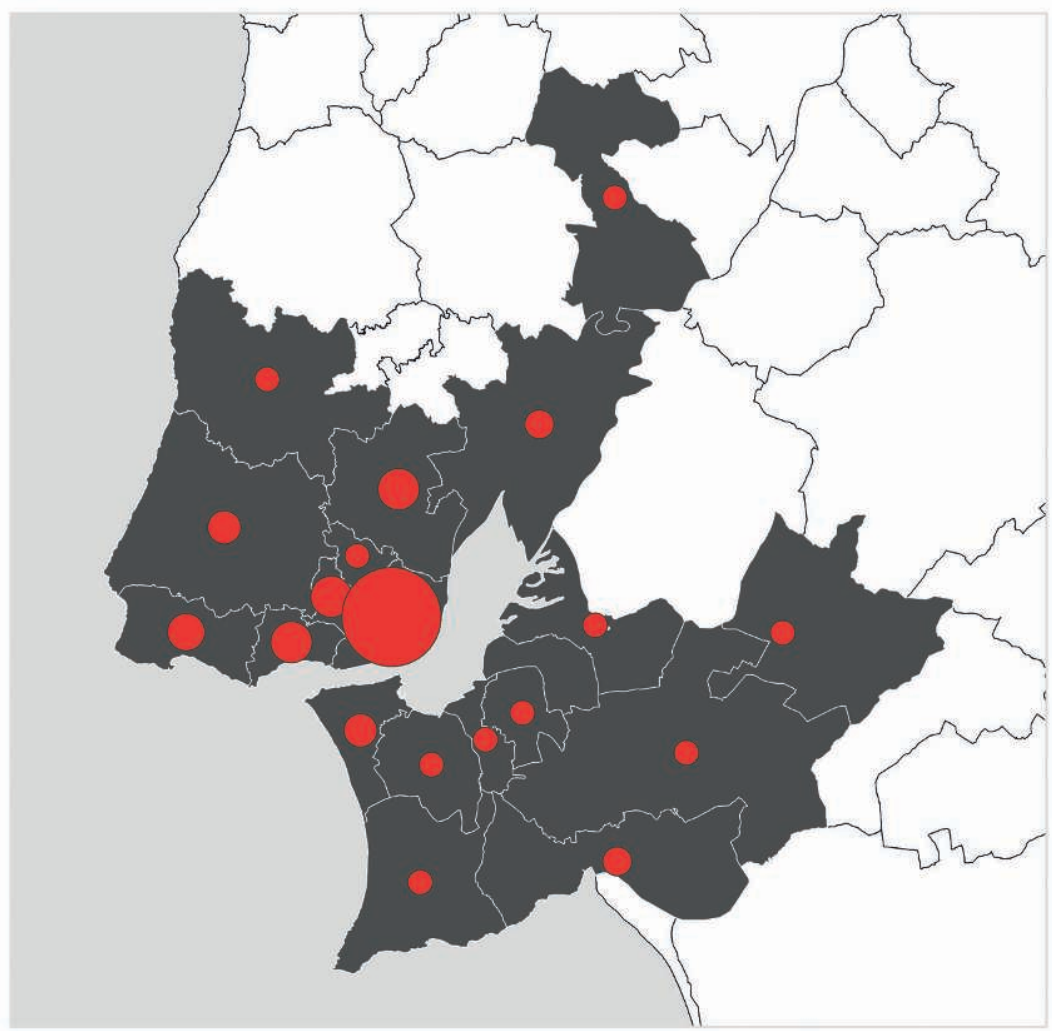

Fonte: Elaboração própria 
Arquitectura Portuguesa, e Bandeirinha (2007) que os bairros construídos ao abrigo do SAAL representam a arquitectura do 25 de Abril. Apesar dos elogios metodológicos e conceptuais que foram admitidos nas décadas seguintes, o SAAL teve uma evolução conturbada e acabou por ser paralisado ainda em 1976, o que afectou a construção e a finalização de vários projectos alinhavados.

Por sua vez, a CRP foi fundamental ao consagrar o direito à habitação, no espírito dos direitos defendidos na Declaração Universal dos Direitos Humanos. Contudo, o texto constitucional excessivamente programático não contribuiu para clarificar como e quando o Estado português deve actuar (Antunes, 2018). Esse papel estratégico e programático está, na verdade, reservado para as Leis de Bases, como as que foram criadas para outros direitos económicos, sociais e culturais consagrados na CRP, sem que, no entanto, o mesmo ocorresse para o direito à habitação.

No que se refere à promoção indirecta nos últimos 45 anos, destinada a cooperativas de habitação, iniciativa privada e entidades assistencialistas, vale a pena sublinhar que a construção de habitações com apoio da administração pública foi sempre um nicho de mercado, não obstante as várias alterações legislativas que tinham como objectivo tornar os programas mais atractivos. Importa também notar que as cooperativas demonstraram maior interesse e aptidão para a construção de habitações de interesse social (LNEC, 1989), embora o período mais profícuo tenha ficado reduzido a um espaço de tempo limitado, entre 1985 e 2000, o que coincidiu com o momento em que o mercado privado construiu mais habitações na história do nosso país (Mateus, 2015).

Acresce, ainda, que as habitações construídas ao abrigo de programas de promoção indirecta se destinaram fundamentalmente à classe média solvente, com capacidade para aceder ao crédito à habitação. Significa isto que as famílias destinatárias destes programas não foram necessariamente as mais carenciadas, mas, sim, a classe média em ascensão e com capacidade para aceder a crédito bancário para a aquisição de casa própria. Este fenómeno fez com que poucas cooperativas de habitação ou empresas privadas tenham permanecido proprietárias das habitações construídas com apoios públicos. Pelo contrário, a quase totalidade desse parque habitacional foi vendido após a construção, pelo que hoje a habitação social portuguesa é esmagadoramente de domínio público.

No que respeita à promoção directa, o PER tornou-se o programa mais importante e marcante da história da habitação portuguesa. No contexto da entrada de Portugal na Comunidade Económica Europeia, o desenvolvimento do PER possibilitou a construção de dezenas de milhares de habitações por todo o país, aumentando de forma significativa o parque habitacional municipal. A década de 1990 foi não só o momento mais importante para a construção de habitação pública, como o único da história da habitação portuguesa em que existiu um claro desígnio nacional de erradicar situações chocantes de indignidade humana.

Actualmente, o parque de habitação pública corresponde a 118000 fogos ( $2 \%$ no parque habitacional nacional), propriedade de municípios, regiões autónomas e administração central, que proporcionam uma habitação a cerca de 113000 agregados familiares, englobando aproximadamente 270000 indivíduos (2,5\% da população portuguesa).

Como vimos anteriormente, no nosso país a habitação social é quase na totalidade propriedade pública, sendo reduzidas as entidades privadas, cooperativas ou assistencialistas que não alienaram em definitivo as habitações construídas com apoios. Paralelamente, o parque de habitação social que subsiste foi construído no contexto específico de programas de realojamento, pelo que existe uma oferta muito residual de habitação pública, cooperativa ou privada destinada a promover o acesso à habitação a famílias da classe média com dificuldades para garantir uma habitação no mercado livre.

De acordo com um estudo apresentado em $2015^{30}$ sobre as dotações do Orçamento do Estado executadas no período 1987-2011, foi reconhecido que dos 9,6 mil milhões de euros investidos em políticas de habitação, 73,3\% foram destinados para apoios à pessoa, nomeadamente para bonificações de juros no crédito à habitação, sendo que apenas $16,1 \%$ foram aplicados em programas de promoção directa e $0,1 \%$ em programas de promoção indirecta. ${ }^{31}$ Tendo sido este o momento mais importante de construção habitacional no nosso país, pode-se concluir que nos últimos 45 anos a "estratégia" habitacional se consubstanciou na bonificação de juros no crédito à habitação, que aglutinou o esforço financeiro e colocou em segundo plano as restantes opções, como a promoção indirecta ou a promoção directa de habitação social.

Conforme analisado, o desenvolvimento das políticas de habitação social em Portugal foi casuístico, sem continuidade, sistematização temporal nem estratégia a médio e a longo prazo. Actualmente, subsistem graves problemas de acesso a habitação condigna. Tal é comprovado nos dados do INE, de 2011, que indicam a existência de 6612 alojamentos familiares não clássicos, ou no levantamento promovido pelo IHRU, em 2018, que identificou 25762 famílias a residir em situações insatisfatórias em território nacional. Note-se que algumas destas ocorrências se traduzem, ainda, na subsistência de bairros de habitações precárias, com alojamentos construídos com materiais módicos, sem electricidade, água canalizada, saneamento básico ou ilu- 
minação pública. Fazendo a democracia portuguesa 45 anos em 2019, restará saber se, quando fizer meio século, ainda tolerará a existência de situações habitacionais que violam os direitos humanos mais elementares.

\section{Notas}

1 Para este trabalho foi analisado o conteúdo directo de cerca de 30 diplomas legislativos, todos referidos ao longo do texto, assim como de várias dezenas de portarias e diplomas de alteração.

2 Despacho conjunto dos Ministérios da Administração Interna e do Equipamento Social e do Ambiente, datado de 31 de Julho e publicado a 6 de Agosto de 1974.

3 Despacho de 28 de Outubro de 1976.

${ }^{4}$ Revisão constitucional de 1982.

${ }^{5}$ Revisão constitucional de 2001.

${ }^{6}$ Decreto-Lei n. ${ }^{\circ}$ 730/74, de 20 de Dezembro

7 Decreto-Lei n. ${ }^{\circ}$ 737-A/74, de 23 de Dezembro.

8 Decreto-Lei n. ${ }^{\circ}$ 515/77, de 14 de Dezembro.

9 Decreto-Lei n. ${ }^{\circ}$ 268/78, de 31 de Agosto.

10 Decreto-Lei n. ${ }^{\circ} 454 / 80$, de 9 de Outubro; alterado, entretanto, em 1996 e em 2015.

${ }_{11}$ Decreto-Lei n. ${ }^{\circ} 218 / 82$, de 2 de Junho.

12 Portaria n. ${ }^{\circ}$ 580/83, de 17 de Maio.

13 Portaria n. ${ }^{\circ} 828 / 88$, de 29 de Dezembro.

${ }^{14}$ Estatística Industriais - Estatísticas da Construção e da Habitação.

15 Decreto-Lei n. ${ }^{\circ} 663 / 74$, de 26 de Novembro.

16 Decreto-Lei n. ${ }^{\circ} 36$ 212, de 7 de Abril 1947.

17 Decreto-Lei n. ${ }^{\circ}$ 608/73, de 14 de Novembro.

18 Decreto-Lei n. ${ }^{\circ} 236 / 85$, de 5 de Julho.

19 Decreto-Lei n. ${ }^{\circ}$ 165/93, de 7 de Maio.

${ }^{20}$ Estatística Industriais - Estatísticas da Construção e da Habitação.

${ }^{21}$ Portaria n. ${ }^{\circ}$ 580/83, de 17 de Maio.

22 Portaria n. ${ }^{\circ} 828 / 88$, de 29 de Dezembro.

23 Portaria n. ${ }^{\circ} 500 / 97$, de 21 de Julho.

24 Decreto-Lei n. ${ }^{\circ} 220 / 83$, de 26 de Maio.

${ }^{25}$ Decreto-Lei n. ${ }^{\circ} 110 / 85$, de 17 de Abril.

26 Decreto-Lei n. ${ }^{\circ} 163 / 93$, de 7 de Maio

27 Decreto-Lei n. ${ }^{\circ}$ 135/2004, de 3 de Junho.

${ }^{28}$ Decreto-Lei n. ${ }^{\circ} 37 / 2018$, de 4 de Junho.

29 Decreto-Lei n. ${ }^{\circ}$ 29/2018, de 4 de Maio.

${ }^{30}$ Resolução do Conselho de Ministros n. ${ }^{\circ}$ 48/2015.

31 O remanescente foi aplicado em apoios ao arrendamento, reabilitação e segurança social.

\section{Referências bibliográficas}

Acciaiuoli, M. (2015). Casas com escritos - uma história da habitação em Lisboa. Lisboa: Bizâncio.

Agarez, R. (Coord.). (2018). Habitação - cem anos de políticas públicas em Portugal 1918-2018. Lisboa: Instituto da Habitação e da Reabilitação Urbana.

Allen, J., Barlow, J. Leal, J. Maloutas, T., \& Padovani, L. (2004). Housing \& welfare in southern Europe. Oxford: Blackwell Publishing.

Antunes, G. (2018). Políticas de habitação - 200 anos. Lisboa: Caleidoscópio e Câmara Municipal de Lisboa.

Balchin, P. (Ed.). (1996). Housing policy in Europe. Londres: Routledge.

Bandeirinha, J. (2007). O processo SAAL e a Arquitectura no 25 de Abril de 1974. Coimbra: Imprensa da Universidade de Coimbra.

Baptista, L. (1999). Cidade e Habitação Social: o Estado Novo e o Programa de Casas Económicas em Lisboa. Oeiras: Celta.

Baptista, L. (2001). Cidade e Políticas Sociais de Habitação - Armadilhas Conceptuais e Metodológicas. Cidades Comunidades e Territórios, 3, 71-81.

Bargelli, E., \& Heitkamp, T. (2018). New Developments in Southern European Housing. Pisa: Pisa University Press.

Cachado, R. A. (2013). O Programa Especial de Realojamento - ambiente histórico, político e social. Análise Social, 206(XLVIII), 135-152.

Cerezales, D. (2003). O poder caiu na rua - crise de Estado e acções colectivas na revolução portuguesa 1974-1975. Lisboa: Instituto de Ciências Sociais.

CET. (1994). Cooperativas de habitação de Lisboa situação e perspectivas. Lisboa: Observatório da Habitação.

CNS. (1976). Livro branco do SAAL. Vila Nova de Gaia: Conselho Nacional do SAAL.

Coelho, A. B., \& Coelho, P. R. (2009). Habitação de interesse social em Portugal 1988-2005. Lisboa: Livros Horizonte.

Coelho, A. B. (2006). 1984 - 2004, 20 anos a promover a construção de habitação social. Lisboa: Instituto da Habitação e da Reabilitação Urbana.

Coelho, A. B. (2013). Os anos dourados dos conjuntos cooperativos de habitação económica (1974-1984). In. N. Portas (coord.). Habitação para o maior número, Portugal, os anos de 1950-1980. Lisboa: Instituto da Habitação e da Reabilitação Urbana.

DCH. (1990). Boletim Departamento de Construção de Habitação n. ${ }^{\circ}$ 52. Lisboa: Departamento de Construção de Habitação / Câmara Municipal de Lisboa.

Decreto-Lei n. ${ }^{\circ} 36$ 212, de 7 de Abril. Diário do Governo n. 0 78/1947 - Série I. Lisboa: Ministérios das Finanças e das Obras Públicas

Decreto-Lei n. ${ }^{\circ}$ 608/73 de 14 de Novembro. Diário do Governo n. ${ }^{\circ}$ 266/1973, 1. ${ }^{\circ}$ Suplemento - Série I. 
Lisboa: Ministério das Obras Públicas - Secretaria de Estado do Urbanismo e Habitação

Decreto-Lei n. ${ }^{\circ} 110 / 85$ de 17 de Abril. Diário da República n.o 89/1985 - Série I. Lisboa: Ministério do Equipamento Social

Decreto-Lei n.o 135/2004 de 3 de Junho. Diário da República n.o 130/2004 -- Série I-A. Lisboa: Ministério das Obras Públicas, Transportes e Habitação

Decreto-Lei n. o 163/93 de 7 de Maio. Diário da República n.o 106/1993 - Série I-A. Lisboa: Ministério das Obras Públicas, Transportes e Comunicações

Decreto-Lei n.o 165/93 de 7 de Maio. Diário da República n.o 106/1993 - Série I. Lisboa: Ministério das Obras Públicas, Transportes e Comunicações

Decreto-Lei n. ${ }^{\circ}$ 218/82 de 2 de Junho. Diário da República n.o 125/1982 - Série I. Lisboa: Presidência do Conselho de Ministros

Decreto-Lei n. ${ }^{\circ} 220 / 83$ de 26 de Maio. Diário da República n.o 121/1983 - Série I. Lisboa: Ministérios das Finanças e do Plano e da Habitação, Obras Públicas e Transportes

Decreto-Lei n. 0 236/85 de 5 de Julho. Diário da República n.o 152/1985 - Série I. Lisboa: Ministério do Equipamento Social

Decreto-Lei n.o 268/78 de 31 de Agosto. Diário da República n.o 287/1977, Série I. Lisboa: Ministério da Habitação e Obras Públicas - Gabinete do Ministro

Decreto-Lei n. ${ }^{0}$ 29/2018 de 4 de Maio. Diário da República n.o 86/2018, Série I. Lisboa: Presidência do Conselho de Ministros

Decreto-Lei n. 0 37/2018 de 4 de Junho. Diário da República n.o 106/2018, Série I. Lisboa: Presidência do Conselho de Ministros

Decreto-Lei n. 0 454/80 de 9 de Outubo. Diário da República n.o 234/1980 - Série I. Lisboa: Presidência do Conselho de Ministros - Gabinete do Ministro Adjunto do Primeiro-Ministro

Decreto-Lei n. 0 515/77 de 14 de Dezembro. Diário da República n.o 287/1977 - Série I. Lisboa: Ministérios das Finanças e da Habitação, Urbanismo e Construção

Decreto-Lei n. 0 663/74 de 26 de Novembro. Diário do Governo n.o 275/1974 - Série I. Lisboa: Ministérios das Finanças e do Equipamento Social e do Ambiente

Decreto-Lei n. 0 730/74 de 20 de Dezembro. Diário do Governo n.o 296/1974 - Série I. Lisboa: Ministérios da Justiça e do Equipamento Social e do Ambiente

Decreto-Lei n. 0 737-A/74 de 23 de Dezembro. Diário do Governo n.o 298/1974 - Série I. Lisboa: Ministério do Equipamento Social e do Ambiente - Secretaria de Estado da Habitação e Urbanismo

Despacho de 28 de Outubro. Diário da República n.o 253/1976 - Série I. Lisboa: Presidência do ConseIho de Ministros - Secretaria de Estado da Comunicação Social - Gabinete do Secretário de Estado

Despacho de 6 de Agosto. Diário do Governo n. 0 182/1974 - Série I. Lisboa: Ministérios da Administração Interna e do Equipamento Social e do Ambiente
Dias, J. (1994). Tendências das políticas europeias quanto aos modelos de habitação social. Sociedade e Território, 20, 91-100.

Farha, L. (2017). Report of the Special Rapporteur on adequate housing as a component of the right to an adequate standard of living, and on the right to non-discrimination in this context, on her mission to Portugal. Nova Iorque: Nações Unidas.

FENACHE (1991). As Cooperativas de Habitação e sua actividade - primeiros resultados de um levamento. Porto: Centro de Estudos do Cooperativismo Habitacional.

FENACHE (1992). Habitação cooperativa em Portugal 1974-1991. Lisboa: Federação Nacional de Cooperativas de Habitação Económica.

Ferreira, A. F. (1987). Por uma nova política de habitação. Lisboa: Edições Afrontamento.

Ferreira, A. F. (1993). Livro branco sobre a política da habitação em Portugal. Lisboa: Encontro Nacional da Habitação.

FFH. (1979). Cooperativas de habitação em Portugal. Lisboa: Ministério da Habitação e Obras Públicas - Secretaria de Estado da Habitação [relatório policopiado].

FFH. (1980). A gestão nas cooperativas de habitação. Lisboa: Fundo de Fomento da Habitação [relatório policopiado].

Freitas, M. J. (1994). Os paradoxos do realojamento Sociedade e Território, 20, 26-34.

Freitas, M. J. (1998). Pensar os espaços domésticos em contextos de realojamento. Sociedade e Território, 25/26, 150-161

Freitas, M. J. (2002). Aprendizagens num percurso de autonomias e poderes - o processo de realojamento em Cascais. Cidades. Comunidades e Territórios, 4, 19-32.

Gros, M. C. (1994). Pequena História do Alojamento Socia em Portugal. Sociedade e Território, 20, 80-90.

Guerra, I. (1994). As pessoas não são coisas que se ponham em gavetas. Sociedade e Território, 20, 11-16.

Guerra, I. (2011). As políticas de habitação em Portugal: à procura de novos caminhos. Cidades - Comunidades e Territórios, 22, 41-68.

Guerra, I. (Coord.). (1999). Diagnóstico sobre a Implementação do programa PER nos municípios das Áreas Metropolitanas de Lisboa e Porto. Lisboa: Instituto Nacional de Habitação.

Hughes, D., \& Lowe, S. (2000). Public sector housing law. Londres: Reed Elsevier.

IHRU. (2015). 1987-2011 - 25 anos de esforço do Orçamento do Estado com a habitação. Instituto da Habitação e da Reabilitação Urbana. Lisboa: IHRU.

Lei Constitucional n.o 1/2001. Diário da República n.o 286/2001 - Série I-A de 2001-12-12. Lisboa: Assembleia da República

Lei Constitucional n.o 1/82. Diário da República n.o 227/1982 - Série de 1982-09-30I. Lisboa: Assembleia da República 
LNEC. (1989). Análise dos empreendimentos apoiados pelo INH. Lisboa: Laboratório Nacional de Engenharia Civil [relatório policopiado].

Lowe, S. (2011). The housing debate. Bristol: University of Bristol.

Lund, B. (2016). Housing politics in the United Kingdom. Bristol: Policy Press University of Bristol.

Malpass, P., \& Murie, A. (1999). Housing policy and practice. Nova Iorque: Palgrave Macmillan.

Mateus. A. (Coord.). (2015). Três décadas de Portugal Europeu - balanço e perspectivas. Lisboa: Fundação Francisco Manuel dos Santos.

Matos, F. (1994). Habitação cooperativa no grande Porto. Revista da Faculdade de Letras - Geografia, X/XI, 19-38.

McCrone, G., \& Stephens, M. (2017). Housing policy in Britain and Europe. Routledge: Londres.

Mullins, D., \& Murie, A. (2006). Housing policy in the UK. Nova Iorque: Palgrave Macmillan.

Paiva, F. (1997). Estudo de caracterização das cooperativas de habitação em Portugal. In. As cooperativas de habitação em Portugal. Lisboa: Instituto António Sérgio.

Pedrosa, P. (2018). As cooperativas de habitação portuguesas: O jogo dos possíveis. In R. Agarez, (Coord.), Habitação - cem anos de políticas públicas em Portugal 1918-2018. Lisboa: Instituto da Habitação e da Reabilitação Urbana.

Pinto, P. (2008). Urban social movements and the transition to democracy in Portugal - 1974-1976. The Historical Journal, 51(4), 1025-1046.

Pinto, P. (2013). Lisbon rising: urban social movements in the portuguese revolution - 1974-75. Manchester: Manchester University Press.

Pinto, T. C. (1994). A apropriação do espaço em bairros sociais: o gosto pela casa e o desgosto pelo bairro. Sociedade e Território, 20, 36-43.

Portaria n. 0 500/97 de 21 de Julho. Diário da República n. ${ }^{0}$ 166/1997 - Série I-B. Lisboa: Ministério do Equipamento, do Planeamento e da Administração do Território

Portaria n. ${ }^{\circ}$ 580/83 de 17 de Maio. Diário da República n.o 113/1983 - Série I. Lisboa: Ministério da Habitação, Obras Públicas e Transportes

Portaria n. ${ }^{\circ}$ 580/83 de 17 de Maio. Diário da República n.o 113/1983 - Série I. Lisboa: Ministério da Habitação, Obras Públicas e Transportes
Portaria n. 0 828/88 de 29 de Dezembro. Diário da República n. 0 300/1988 - Série I. Lisboa: Ministério das Obras Públicas, Transportes e Comunicações

Portaria n. ${ }^{\circ}$ 828/88 de 29 de Dezembro. Diário da República n.o 300/1988 - Série I. Lisboa: Ministério das Obras Públicas, Transportes e Comunicações

Portas, N. (Coord.) (2013). Habitação para o maior número, Portugal, os anos de 1950-1980. Lisboa: Instituto da Habitação e da Reabilitação Urbana.

Resolução do Conselho de Ministros n. ${ }^{4}$ 48/2015. Diário da República n.o 136/2015, Série I. Lisboa: Presidência do Conselho de Ministros

Santos, B. S. (2017). As bifurcações da ordem - revolução, cidade, campo e indignação. Coimbra: Almedina.

Serpa, F. (Coord). (2018). Habitação de promoção pública: da construção nova a reabilitação, uma leitura dos projectos. In R. Agarez (Coord.), Habitação - cem anos de políticas públicas em Portugal 1918-2018. Lisboa: Instituto da Habitação e da Reabilitação Urbana.

Serra, N., (2002). Estado, território e estratégias de habitação. Coimbra: Quarteto Editora.

Silva, C. N. (1994a). 1926-1974 Política urbana em Lisboa. Lisboa: Livros Horizonte.

Silva, C. N. (1994b). Mercado e políticas públicas em Portugal: a questão da habitação na primeira metade do século XX. Análise Social, XXIX, 655-676.

Silva, C. N. (1994c). Política e gestão municipal em Lisboa no século $X X$ : situação e perspectivas da investigação. Lisboa: Revista Penélope, 13, 163-173.

Silva, C. N. (1997). Política urbana em Lisboa: elementos para uma periodização. I Colóquio Temático, $O$ município de Lisboa e a dinâmica urbana (séculos XVI-XIX), 293-306.

Vieira, A. S. (1986). O 25 de Abril e a transformação da cidade. Revista Crítica de Ciências Sociais, 18, $19,20,37-40$.

Xerez, R., Rodrigues, P., \& Cardoso, F. (2018). A política de habitação em Portugal de 2002 a 2017: Programas, políticas públicas implementadas e instituições envolvidas. In R. Agarez (Coord.), Habitação - cem anos de políticas públicas em Portugal 1918-2018. Lisboa: Instituto da Habitação e da Reabilitação Urbana.

Recebido a 14/02/2019. Aceite para publicação a 30/03/2019

Gonçalo Antunes (goncalo.antunes@fcsh.unl.pt) Centro Interdisciplinar de Ciências Sociais (CICS.NOVA), Faculdade de Ciências Sociais e Humanas (NOVA FCSH). Avenida de Berna, 26, 1069-061 Lisboa. 